The East African Medical Journal Vol. 81 No. 1 January 2004

SERUM PROSTATE SPECIFIC ANTIGEN LEVELS IN MEN WITH BENIGN PROSTATIC HYPERPLASIA AND CANCER OF PROSTATE.

A. Amayo, MBChB (Nbi) M.Med (Pathology) (Nbi), Lecturer, Department of Clinical Chemistry, University of Nairobi, P.O. Box 19676, Nairobi, W. Obara, HND (Biochemistry), Senior Technologist, Nairobi Hospital Laboratory

Request for reprints to: Dr. Angela Amayo, MBChB (Nbi) M.Med (Pathology) (Nbi) Lecturer, Department of Clinical Chemistry, University of Nairobi, P.O. Box 19676, Nairobi

\title{
SERUM PROSTATE SPECIFIC ANTIGEN LEVELS IN MEN WITH BENIGN PROSTATIC HYPERPLASIA AND CANCER OF PROSTATE
}

\author{
A. AMAYO and W. OBARA
}

\begin{abstract}
Objective: To determine the sensitivity, specificity and positive predictive value of the PSA test at the conventional cut-off value of $4 \mathrm{ng} / \mathrm{ml}$.

Design: Retrospective study.

Setting: Nairobi Hospital Laboratory, Nairobi.

Data Source: Results of serum Prostate specific Antigen (PSA), estimation and prostate histology specimens at the Nairobi Hospital Laboratory between January 1997 and December 1999.

Results: A total of 3309 PSA tests and 524 prostate biopsies were processed during the study period. One hundred cases had both PSA test and histology, where the PSA test was done before the surgical procedure. Fourty nine of them had histological diagnosis of cancer of prostate (CAP) while 71 had benign prostate hyperplasia (BPH). There was considerable overlap in the PSA concentrations between the two groups, the ranges being 0.34-36 $\mathrm{ng} / \mathrm{ml}$ and 1.78-4339 $\mathrm{ng} / \mathrm{ml}$ for BPH and CAP respectively. $63.4 \%$ of BPH subjects had PSA concentrations above the $4 \mathrm{ng} / \mathrm{ml}$ threshold value; $29.6 \%$ being in the diagnostic gray zone of 4-10 $\mathrm{ng} / \mathrm{ml}$. In contrast only $6 \%$ of CAP subjects had PSA values in the gray zone. Using the $4 \mathrm{ng} / \mathrm{ml}$ cut-off, the sensitivity, specificity and positive predictive value of the PSA test were $89.8,37$ and $49 \%$ respectively.

Conclusion: Although PSA is a sensitive test, it is not sufficiently specific to discriminate between BPH and CAP at intermediate values. Additional approaches are required to enhance its specificity for CAP screening without reducing the sensitivity.
\end{abstract}

\section{INTRODUCTION}

Prostate Specific Antigen (PSA), a member of the human kallikrein gene family, is a serine protease with chymotrypsin-like activity. produced mainly by the epithelial cells that line the acini and ducts of the prostate gland. PSA is secreted into the seminal fluid in high concentrations where it's main physiological function is to liquefy the seminal gel $(1,2)$. Small amounts of PSA are normally found in circulation as a result of leakage from the prostate gland. However, disruption of the normal glandular structure by prostatic disease allows greater amounts of PSA to enter the general circulation.

Serum PSA determinations are widely used to monitor and manage patients with established prostate cancer (CAP). Serial monitoring of post-prostatectomised patients for increased serum PSA is a common approach for the detection of recurrent or metastatic disease(3$5)$. Cancer of prostrate is one of the most common malignancies in men(4,6,7). It is potentially curable when found localised within the prostate gland. Unfortunately, when it has spread beyond the confines of the gland, CAP is a uniformly fatal disease $(8,9)$.
Because of the poor prognosis of advanced CAP, determination of serum PSA concentration has been recommended as a screening test for CAP(4,10-12). Population based screening for CAP using PSA remains controversial because of insufficient evidence that early detection and aggressive treatment of CAP can reduce mortality $(8,13)$. Despite this, the use of PSA testing as part of regular physical check-ups in men over 50 years of age has continued to increase.

Prostate Specific Antigen is however not specific for CAP and non-malignant prostatic diseases, including prostatitis and benign prostatic hyperplasia (BPH) are also associated with elevations of serum $\operatorname{PSA}(3,4,14)$. Increases in serum PSA are however more frequent and higher in CAP and early crosssectional analysis indicated that the diagnostic "grayzone" is in the PSA range of $4-10 \mathrm{ng} / \mathrm{ml}$, prostate biopsy being indicated in those with PSA > $10 \mathrm{ng} /$ $\mathrm{ml}(4,15,16)$. Since PSA testing was introduced in this laboratory, its utility as a screening tool for CAP has increased. The purpose of this study was to evaluate its sensitivity, specificity and positive predictive value for early detection of CAP since there is little local data on the subject. 


\section{MATERIALS AND METHODS}

This was a retrospective study. All results of PSA done at the Nairobi Hospital laboratory between January 1997 and December 1999 were considered. Results of prostate histologies done in the same period were also looked at. Subjects who had both PSA estimation and prostate histology were further evaluated. The cases of BPH and CAP were defined by histological diagnosis of benign or malignant prostate lesions respectively. Because prostate surgery can cause substantial elevation of PSA for upto four weeks(4), only those subjects who had PSA estimation done before the surgical procedure were considered.

Permission was obtained from the institutional review board. PSA estimation was done using a microparticle immunoassay technique on the Abbott IMX and Abbott AXSYM (Abbott Park IL.)

Prostate biopsy specimens were processed according to standard histological procedures(17). The conventional PSA cut-off of $4 \mathrm{ng} / \mathrm{ml}$ was used for grouping PSA results into normal and high values. Sensitivity, specificity and positive predictive values of the PSA test were calculated at this cutoff value and at $10 \mathrm{ng} / \mathrm{ml}$.
Statistical analysis: Data were entered into a PC and analysis done using MS Excel software (Microsoft). Data were summarised using means, medians and percentiles. Sensitivity was calculated as the number of CAP cases testing positive divided by the total number of CAP cases. Specificity was calculated as the number of BPH cases testing negative divided by the total number of $\mathrm{BPH}$ cases. Positive predictive value was calculated as the number of CAP cases testing positive divided by the total number with positive test results.

\section{RESULTS}

A total of 3309 PSA estimations and 524 prostate specimens were processed during the study period (Fig. 1) There was a steady increase in the number of PSA tests done, prostate specimens processed and CAP cases detected over this period. Fourty nine cases of CAP and seventy one of BPH met the study requirements. The median PSA concentrations in the BPH and CAP subjects were $6.14 \mathrm{ng} / \mathrm{ml}$ and $58.3 \mathrm{ng} / \mathrm{ml}$ respectively. There was an overlap in the PSA values between these two groups, the ranges being 0.34 - 36 and $1.78-4339$ $\mathrm{ng} / \mathrm{ml}$ for BPH and CAP respectively (Figure 2).

Figure 1

Summary of PSA tests, prostate biopsies and CAP cases

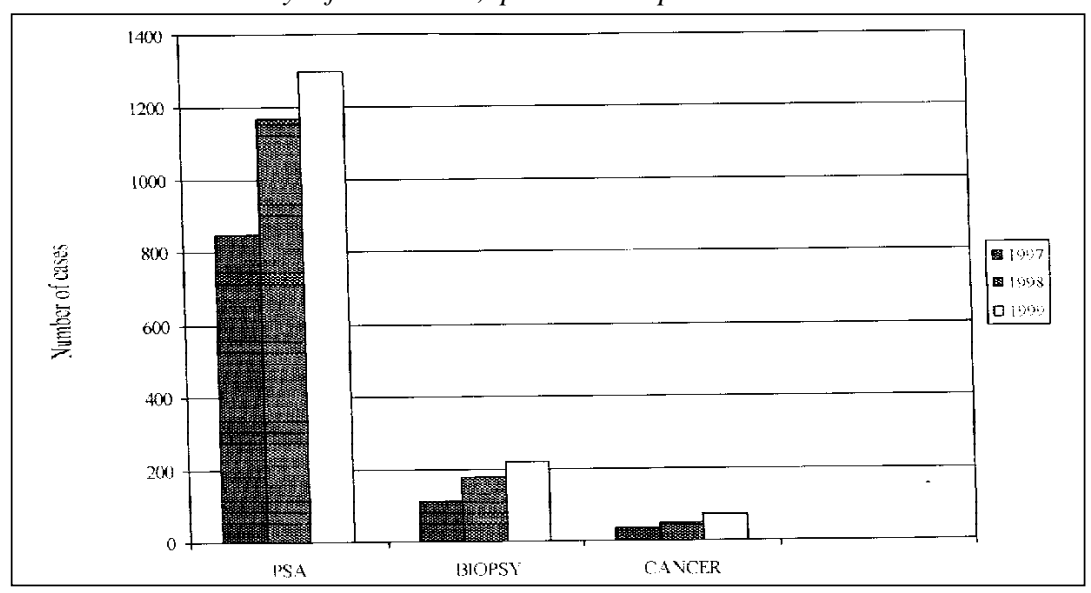

Figure 2

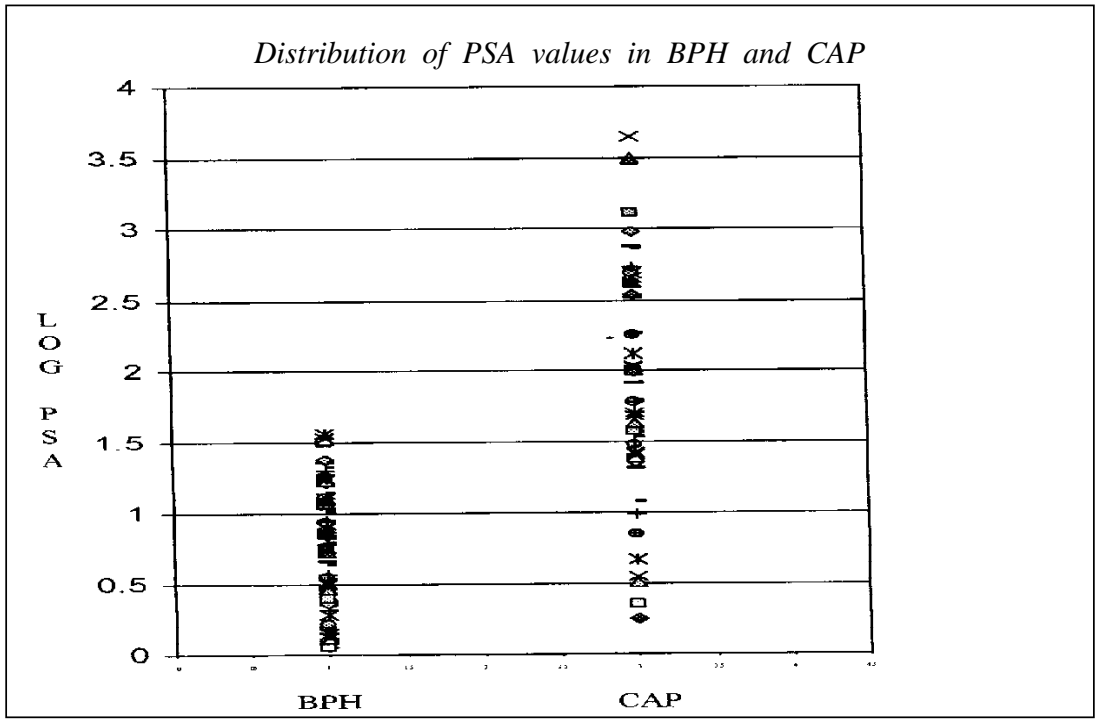


Table 1

Distribution of PSA values $(\mathrm{ng} / \mathrm{ml})$ in $B P H$

and $C A P$

\begin{tabular}{|c|c|c|c|c|c|c|c|}
\hline Mean PSA $\bullet \pm$ SD & 25 th & $\begin{array}{l}\text { Percentiles } \\
\text { 50th }\end{array}$ & 75th & PSA $<4$ & PSA $4-10$ & $\mathrm{PSA}>10$ & Total \\
\hline ВРН $8.8 \pm 8.7$ & 2.06 & 6.14 & 12.8 & $26(36.6 \%) \bullet$ & $12(29.6 \%)$ & $24(33.8 \%)$ & 71 \\
\hline CAP $332.9 \pm 774$ & 24.53 & 58.3 & 333 & $5(10.2 \%)$ & $3(6 \%)$ & $41(83.7 \%)$ & 49 \\
\hline
\end{tabular}

-Number (Percentage)

$\bullet \mathrm{ng} / \mathrm{ml}$

Table 2

Clinical sensitivity and specificity of PSA at various cutoff values

\begin{tabular}{llll}
\hline Cutoff & Sensitivity & Specificity & $\begin{array}{l}\text { Positive } \\
\text { Predictive value } \\
\%\end{array}$ \\
\hline $\mathrm{ng} / \mathrm{ml}$ & $\%$ & $\%$ & 49 \\
\hline 4 & 89.8 & 37 & 63 \\
\hline
\end{tabular}

Many BPH subjects (63.4\%), had PSA concentrations above the cut-off of $4 \mathrm{ng} / \mathrm{ml}, 29.6 \%$ being in the diagnostic gray zone range $(4-10 \mathrm{ng} / \mathrm{ml})$ (Table I ) In contrast, only $6 \%$ of CAP subjects had PSA concentrations in this range. Using $4 \mathrm{ng} / \mathrm{ml}$ as the cutoff, the sensitivity, specificity and positive predictive value of the PSA test were 89.8, 37\% and $49 \%$ respectively (Table 2). Raising the cut-off to $10 \mathrm{ng} /$ $\mathrm{ml}$ increases the specificity and PPV to 66 and 63\% respectively, while the sensitivity is reduced to $83.7 \%$.

\section{DISCUSSION}

Prostate Specific Antigen (PSA) is an established marker for treatment monitoring of CAP. Annual PSA testing, together with digital rectal examination (DE), has also been recommended in men beginning at the age of 50 as a screening test for prostate cancer $(4,10$ 12 ). Validation of a screening test for cancer requires several criteria to be satisfied(18). The disease must represent a substantial health burden; the test must be able to identify the disease in an asymptomatic localised stage, the screening test must have acceptable values for sensitivity, specificity and predictive value. The curative potential must be substantially better in early compared to advanced disease stages, and cases detected by the screening test experience an improved outcome compared with those who have not been screened. Other issues concern the potential harm of unnecessary investigations and therapies following screening and the cost of the screening test. Screening for CAP using PSA testing has satisfied the first two criteria. It is accepted that prostate cancer is a significant health problem, and testing for serum PSA can identify cancers at an asymptomatic localised stage $(4,8,19)$. The last three criteria and concerns about the potential harm and cost of screening are however the subject of controversy $(8,13,20,21)$. In spite of this, many clinicians have adopted the program of annual testing of individuals. In this study there was a steady increase in the utilisation of the PSA test. The number of prostate biopsies performed and CAP detected over the three years also increased, as is expected in a screening program(6,22).

The results show an overlap in serum PSA concentrations among men with $\mathrm{BPH}$ and CAP, with $63 \%$ of $\mathrm{BPH}$ cases having PSA concentrations more than $4 \mathrm{ng} / \mathrm{mh}$. This is in keeping with previous reports which showed that men with BPH have PSA elevation in 21 to $86 \%$ of the cases(3,23,24). Stamey and his colleagues in 1987 reported PSA elevation in $86 \%$ of patients with histological diagnosis of $\mathrm{BPH}(3)$, while Catalona and co-workers who measured serum PSA in ambulatory men participating in a voluntary screening program for CAP, found PSA elevation in $47 \%$ of men who were later histologically diagnosed as having $\mathrm{BPH}(23)$. Wolff and colleagues reported that PSA could not sufficiently discriminate between BPH and organ confined prostate cancer. The values overlapped considerably in both groups ranging from $0.5-31.2 \mathrm{ng} /$ $\mathrm{ml}$ in the BPH group and $0.7-37.7 \mathrm{ng} / \mathrm{ml}$ in those with CAP(25) .

The reported specificity of PSA depends on the population of patients being tested. In this study, the specificity was low at $37 \%$, attributed mainly to mild PSA elevations in the BPH patients, $29.6 \%$ of whom had PSA in the range of $4-10 \mathrm{ng} / \mathrm{ml}$. In a large case control study performed by Gann et al, the specificity was found to be $83 \%(11)$. This impressively high specificity was attributed to a low degree of $\mathrm{BPH}$ 
among the controls used in the study. Only seven of the 1098 controls were diagnosed to have BPH. The variation in the specificity at the cut-off of $4.0 \mathrm{ng} / \mathrm{ml}$ may also be related to the volume of the prostate gland (4,25) and presence of an occult cancer outside the biopsy zone $(4,26)$. Stamey recently reassessed the available information on the relationship of serum PSA to CAP and concluded that serum PSA $<10 \mathrm{ng} / \mathrm{ml}$ is not a reliable predictor of $\mathrm{CAP}$, and that $\mathrm{BPH}$ is probably the major contributor to serum PSA between 2-10 $\mathrm{ng} / \mathrm{ml}(26,27)$. Acknowledging the inadequate specificity of intermediate PSA values, several methods have been recommended to improve it. These include determination of PSA density and PSA velocity $(2,28)$, use of age adjusted reference ranges(29) and the ratio of free or complexed PSA to total PSA(15,30-32).

Among the patients with CAP in this study, the PSA concentrations were skewed to the right, with $81 \%$ of the patients having PSA values $>20 \mathrm{ng} / \mathrm{ml}\left(25^{\text {th }}\right.$ percentile $=24.53 \mathrm{ngm}$ ). Studies have shown that levels of PSA greater than $15 \mathrm{ng} / \mathrm{ml}$ substantially increase the risk that CAP is extraprostatic(3,32,33). Partin et al. reported that more than $80 \%$ of men whose preoperative serum PSA exceeded $20 \mathrm{ng} / \mathrm{ml}$ had cancers that were not organ confined(34). Stamey et al in their study showed that majority of CAP patients with serum PSA higher than $15 \mathrm{ng} / \mathrm{ml}$ had microscopic capsular penetration, and at PSA > 40ng/ml, most had pelvic node metastases(3). The purpose of screening is to identify patients with cancers that are at an early stage, which would be indicated by serum PSA concentrations less than $15 \mathrm{ng} / \mathrm{ml}$. In this study less than $20 \%$ of the CAP cases would fall in this category. The possible explanation is that in this group of patients, PSA testing was done for diagnostic purposes in patients who already had clinical features suggestive of CAP. The median PSA concentration in this group (58.3 ng/ml), which was much higher than values reported by others would support this $(24,29)$. Carter et al found median PSA concentrations of 7.7 and 28.8 $\mathrm{ng} / \mathrm{ml}$ in local and metastatic CAP cases respectively(24).

In conclusion, our results show that at the conventional cut-off of $4 \mathrm{ng} / \mathrm{ml}$, serum PSA measurements, though sensitive, are not sufficiently specific to discriminate between patients with $\mathrm{BPH}$ and those with CAP. Using a higher cut-off of $10 \mathrm{ng} / \mathrm{ml}$ appears to gives better specificity but the number of false negative results will increase. The findings support the need for approaches to increase the specificity of the PSA test for values in the gray-zone, without reducing the sensitivity of the test. In patients who undergo serial annual PSA estimations, the increase in PSA over time, (PSA velocity) would be useful. However for single PSA determinations, the estimation of the other molecular forms of PSA (free or complexed) when total PSA concentrations are in the range 4-20ng/ $\mathrm{ml}$ is recommended. PSA occurs in serum predominantly in complex with the serine protease inhibitor antichymotrypsin (ACT), while a small amount circulates in a free form(2).

The percentage of free serum PSA is lower in males with prostatic carcinoma than in those with benign prostatic hyperplasia(35). The ratio of free to total PSA has therefore become an important variable for distinguishing between benign and malignant prostate disease. Catalona et al reported that the assay could be used to reduce the number of prostate biopsies that yield negative results, with a minimal loss in the sensitivity of detecting prostate cancer(14). Mitrunen et al found that at $70 \%$ sensitivity, specificity increased from $46 \%$ with total PSA alone to $73 \%$ using the free PSA ratio(32).

\section{ACKNOWLEDGEMENTS}

To Ms. Rachel Ocholla for her help with data collection and entry, the Nairobi Hospital for supporting the study and Ms. E. Karimi for typing the manuscript.

\section{REFERENCES}

1. Lilja, H. Akallikrein - like serine protease in prostatic fluid cleaves the predominant seminal vesicle protein. J. Clin. Invest. 1985; 76:1899-1903.

2. Lilja, H., Christensson, A., Dahlen, U. and Matikaenen, M., et al. Prostate specific antigen in serum occurs predominantly in complex with $\alpha$ 1antichymotrypsin. Clin. Chem. 1991; 37:1618-1625.

3. Stamey, T. A., Yang, N., Hay, A. R., McNeal, J. E. and Freiha, F. S., et al. Prostate specific antigen as a serum marker for adenocarcinoma of the prostate. 1987; 317:909916.

4. American Urological Association. Prostate specific antigen (PSA) best practice policy. Oncology 2000; 14:267-286.

5. Osterling, J. E. Prostate Specific Antigen. A critical assessment of the most useful tumour markers for adenocarcinoma of the prostate. J. Urol. 1991; 145:907-923.

6. Demers, R. Y., Swanson, G. M., and Weiss, L. K. et al. lncreasing incidence of cancer of the prostate. The experience of black and white men in the Detroit metropolitan area. Arch Intern Med. 1994; 154:1211-1216.

7. Olson, C. A. and Goluboff, E. T. Detection and treatment of prostate cancer: Perspective of urologists. J. Urol. 1994; 152:1695-1699.

8. Albertsen, P. C. The role of PSA screening in early detection of prostate cancer. Principles and practice of Oncology updates. 2001; 15:1-15

9. Magoha, G. A. O. Screening and early detection for prostate cancer. East Afri.Med.J. 1997; 74:664-667.

10. Catalona, W., Smith, D. S., Ratliff, T. and Basler, J. W. Detection of organ-confined prostate cancer is increased through prostate-specific antigen-based screening. JAMA, 1993; 270:948-954.

11. Gann, P. H, Hennekens C. H., and Stampfer, M. J. A prospective evaluation of plasma prostate specific antigen for detection of prostatic cancer, JAMA 1995; 273:289-294.

12. Kramer, B. S., Brown, M. L., Prorok, P. C., Potosky, A. L. and Gohagan, J. K. Prostate cancer screening: what we know and what we need to know. Ann. Intern. Med. 1993, 119: 914-923.

13. Krahn, M. D, Mahoney, J. E., and Eckman, M. H. et al: Screening for prostate cancer: A decision analytic view, JAMA 1994; 272:773-780.

14. Catalona, W. J., Smith, D. S., Ornstein, D. K. Prostate cancer detection in men with serum PSA concentrations of 2.6 to $4.0 \mathrm{ng} / \mathrm{ml}$ and benign prostate examination: 
Enhancement of specificity with free PSA measurement. JAMA 1997; 277:1452-1455,

15. Pham Luong, C. C., Kramp, W., Sharp, T., and Soriano, T. F. Evaluation of a two-site immunoradiometric assay for measuring noncomplexed(free) prostate specific antigen. Clin. Chem. 1996; 42:1243-1249.

16. Barry, M. J. Prostate-specific-antigen testing for early diagnosis of prostate cancer. NEJM. 2001; 1373-1377.

17. Kiernan, J. A. Histological and histochemical methods: Theory and Practice $2^{\text {nd }}$ Edition. Pergamon Press 1990: 1050

18. Hulka, B. S. Cancer screening. Degrees of proof and practical application cancer 1988; 62:1776-1780.

19. Aghaji, A. E. and Odoemene, C. A. Prostatic cancer after prostatectomy for benign prostatic hyperplasia in Nigeria. East Afri.Med.J. 2000; 77:635-638.

20. Black, M. H., Grass, C. L., Leinonen, J. and Stenman, U. $\mathrm{H}$. et al. Characterisation of monoclonal antibodies for Prostate specific antigen and development of highly sensitive free prostate specific antigen assays. Clin. Chem.1999; 45:347-354

21. Kroll, M. Prostate cancer screening: Free PSA adds value to PSA testing. Lab. Medica. Inter. 2002; 19:18-19.

22. Potosky, A. L., Miller, B. A. and Albertsen, P. C., et al. The role of increasing detection in the rising incidence of prostate cancer. JAMA 1995; 273:548-552.

23. Catalona, W. J., Smith, D. S. and Ratliff, T. L. et al. Measurement of prostate specific antigen in serum as a screening test for prostate cancer. N. Engl. J. Med. 1991; 324: 1156- 1161 .

24. Carter, H. B., Pearson, J. D., Metter, J. and Brant, L. J. et al. Longitudinal evaluation of prostate specific antigen levels in men with and without prostate disease. JAMA 1992; 267: 2215-2220.

25. Wolff, J. M., Boeckmann, W., Borchers, H. and Handt, S. et al. Prostate specific antigen: insufficient discrimination between benign prostatic hyperplasia and organ confined prostate cancer. Urol. lnt. 1996; 57:170-174.

26. Stamey, T. A. Preoperative serum prostate-specific antigen (PSA). Below $10 \mu \mathrm{g} / \mathrm{L}$ predicts neither the presence of prostate cancer nor the rate of postoperative PSA failure. Clin. Chem. 2001; 47:631-634.
27. Stamey, T. A., Johnstone, I. M. and McNeal, J. E., et al. Preoperative serum prostate specific antigen levels between 2 and $22 \mathrm{ng} / \mathrm{ml}$ correlate poorly with post-radical prostatectomy cancer morphology: prostate specific antigen cure rate appear constant between 2 and $9 \mathrm{ng} / \mathrm{ml}$. J. Urol. 2002; 167:103-111.

28. Benson, M. C., Whang, I. S., Olsson, C. A., et al. The use of prostate specific antigen density to enhance the predictive value of intermediate levels of serum prostate specific antigen. J. Urol. 1992; 147:817-821.

29. Morgan, T. O., Jacobsen, S. J., McCarthy, W. F. Jacobson D. J., et al. Age-specific reference ranges for serum prostate-specific antigen in black men. NEJM 1996; 335:304310.

30. Catalona, W. J., Partin, A. W., Slawin, K. M. and Brawer, M. K., et al. Use of the percentage of free prostate specific antigen to enhance differentiation of prostate cancer from benign disease JAMA. 1998; 279:1542-1547.

31. Pettersson, K., Piironen, T., Seppala, M. and Liukkonen, L. et al. Free and complexed prostate specific antigen (PSA): In vitro stability, epitope map, and development of immunofluorometric assays for specific and sensitive detection of free PSA and $\alpha$ 1alantichymotrypsin complex. Clin. Chem. 1995; 41:1480-1488.

32. Mitrunen, K., Pettersson, K., Piironen, T. and Biork, T., et al. Dual-label one-step immunoassay for simultaneous measurement of free and total prostate specific antigen concentrations and ratios in serum. Clin. Chem. 1995; 41:1115-1120.

33. Coley C. M., Bany, M. J. and Fleming, C. et al. Early detection of prostate cancer: I . Prior probability and effectiveness of tests. Ann. Intern. Med. 1997; 126:394406.

34. Partin, A. W., Kattan, M. W. and Subong, E. N. P., et al. Combination of prostate specific antigen, clinical stage, and Gleason score to predict pathological stage of localised prostate cancer: A multi-institutional update. JAMA 1997; 277:1445-1451.

35. Chistensson, A., Bjork, T., Nilsson, O., Dahlen, U. and Matikainen, M. T. et al. Serum prostate specific antigen complexed to antichymotrypsin as an indicator of prostate cancer. J. Urol. 1993; 150:100-105. 